\title{
Robot-Assisted Laparoscopy Repair for a Supra-Piriform Herniation of the Pelvic Ureter
}

\author{
Clement Destan ${ }^{\mathrm{a}, \mathrm{b}}$, Benoit Molimard ${ }^{\mathrm{a}}$, Paul Chiron ${ }^{\mathrm{a}}$, Marie Dusaud ${ }^{\mathrm{a}}$, \\ Francois-Regis Desfemmes ${ }^{\mathrm{a}}$, Xavier Durand ${ }^{\mathrm{a}}$
}

\begin{abstract}
An 80-year-old woman was diagnosed with an obstructive pyelonephritis by pelvic ureteral hernia supra-piriform. She underwent a robot-assisted laparoscopy repair. Although robot assistance facilitated reparation, rarely frequency location hernia exposed us, radiologist and surgeon, to revise and display anatomy and technic for diagnosis and repair it. The purpose of our case report was to show the computed tomography imaging features and robot laparoscopic technical for repair it.
\end{abstract}

Keywords: Anatomy; Abdominal hernia; Nephritic colic

\section{Introduction}

In France, lithiasis affects $10 \%$ of the population per year, complicated in less than $8 \%$ of cases. The most common cause is urinary stones, responsible for urinary stasis upstream and superinfection of urine. However, anatomical malformations may be responsible for obstruction. The diagnosis is confirmed by scanographic images determining the cause and location of obstruction. We report a rare case, the third case described in the literature, of an obstructive pyelonephritis by pelvic ureteral hernia supra-piriform that has benefited from reconstructive surgery by robot-assisted laparoscopy.

\section{Case Report}

\section{Clinical history}

An 80-year-old woman went to another hospital with right

\section{Manuscript submitted August 5, 2017, accepted August 21, 2017}

aDepartment of Urology, Begin Military Teaching Hospital, 69, Avenue de Paris, 94160 Saint-Mande, Paris, France

bCorresponding Author: Clement Destan, Department of Urology, Begin Military Teaching Hospital, 69, Avenue de Paris, 94160 Saint-Mande, Paris, France. Email : clement.destan@gmail.com

doi: https://doi.org/10.14740/jcs330w lumbar pain and infectious profile not controlled by morphine titration (4 mg). Biological examinations revealed an important inflammatory syndrome (white blood cells: 13,610 cells $/ \mathrm{mm}^{3}$; CRP: $224 \mathrm{mg} / \mathrm{mL}$ ) with preserved renal function. Computed tomography (CT) scan brought to light an incarceration of the pelvic ureter in a right supra-piriform hernia with perineal infiltration and pyelo-ureteritis (Fig. 1). After bacteriological samples, a parenteral probabilistic antibiotic therapy was started by third-generation cephalosporin type ceftriaxone. Then, she was transferred to our hospital for urine drainage. The patient benefited from a double J-probe retrograde surgery on the same day because of the sepsis signs on acute obstructive pyelonephritis.

At the ureter retrograde pyelography (Fig. 2), a stenosed ureter and an omega image compatible with a supra-piriform hernia was noticed. The rise of the Terumo guide and the ureteral probe to the kidney was difficult. The ureter remained in the hernia after the double J stenting. Initial parenteral antibiotherapy had been continued with addition of an aminoglycoside.

Clinical reassessment after $48 \mathrm{~h}$ showed a decrease of pain, apyrexia and normalized biological markers. The urinary bacteriological results demonstrated an E. coli at $10^{7}$. An oral antibiotic relay was performed by a fluoroquinolone for a 15day therapy.

The patient was outgoing at day 2 postoperative with a check-up appointment 15 days after to follow the clinical course, discuss and plan the surgery of this hernia.

Two months after surgery, patient received a curative surgery by ureter reduction and segmental resection with end-toend anastomosis of the right pelvic ureter by robot-assisted laparoscopy.

Once ureter was easily detected in this fit patient, the surgical site was exposed by suspending the left colon and the uterus by threads of percutaneous traction. The dissection of the two legs of the ureter was carried out to the hernia orifice with an attempt of reduction by traction without success due to a too large incarceration and a risk of damage (Fig. 3). The ureter was sectioned on either side of the omega by allowing the loop to fill the supra-piriform orifice. The double probe J was removed, and the two ends were intersected and palletized. The anastomosis was performed in two distinct continuous sutures at the Vicryl with the installation of a new double J probe by endoscopy, without tension and well congruence.

The postoperative follow-up was simple with a postoperative day 2 exit of the hospital.

The ablation of the double $\mathrm{J}$ probe was carried out in con- 

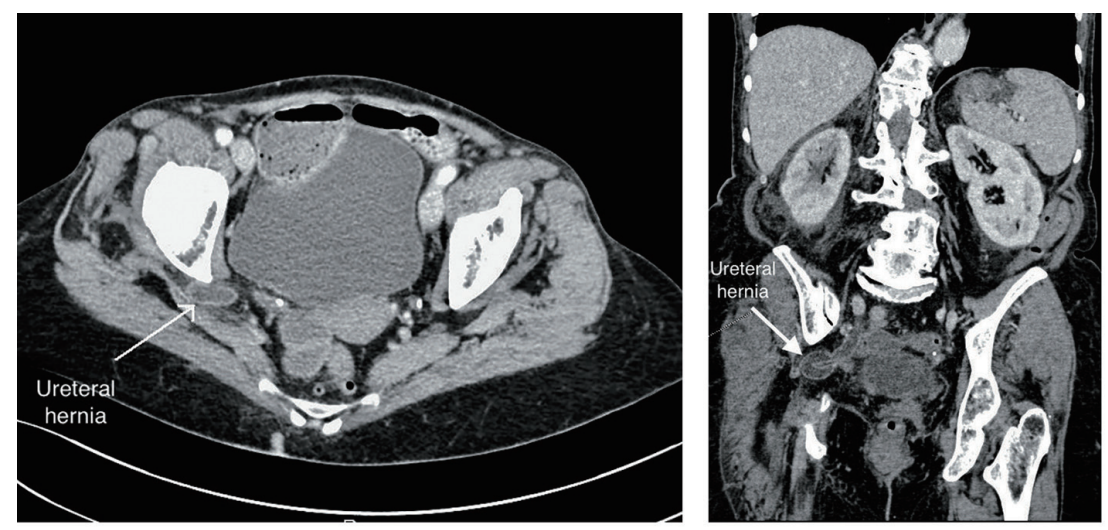

Figure 1. Multiphasic CT images show a right supra-piriform hernia with perineal infiltration and pyelo-ureteritis.

sultation a month later. The patient was reviewed at 3 months of surgery (postoperative) with a urology CT scan describing a segmental ureteral thickening at the anastomosis without stenosis with a comparative drainage of urine on each side.

\section{Discussion}

\section{Anatomical considerations}

The ischiatic foramen represents a transition path between the pelvic region and the gluteal region. Divided into two (large and small ischiatic foramen) by the sacrospinous ligament, several noble elements pass through it [1]. The piriformis muscle is inserted at the anterior part of the sacrum and ends on the great-

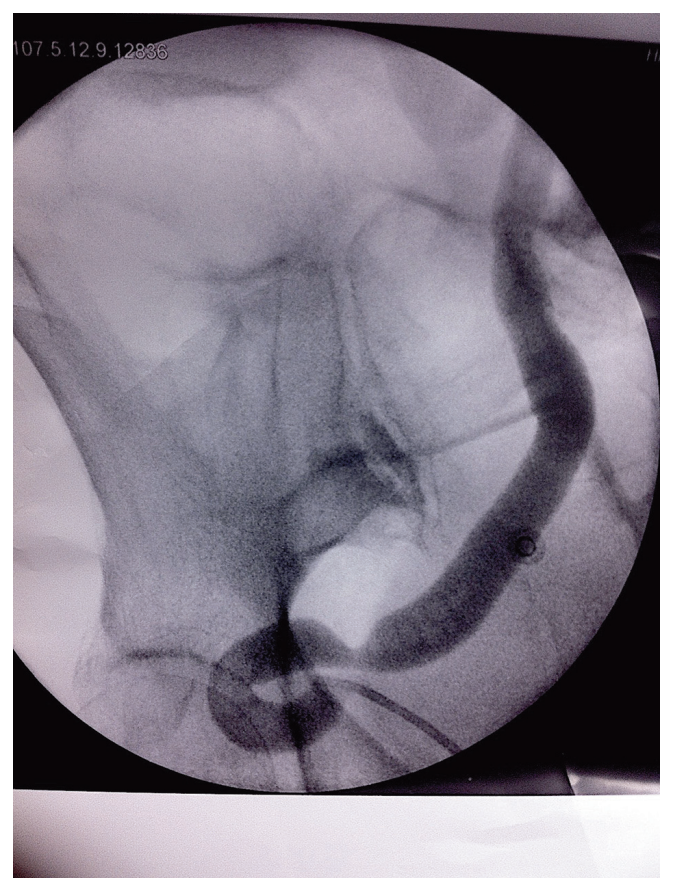

Figure 2. Ureter retrograde pyelography showing pathognomonic omega sign. er trochanter. Thus it delimits the foramen supra- and infra-piriform. Ischiatic hernia is an anatomical defect which is the result of atrophy or abnormal development of the piriformis muscle. Delabie et al studied 104 gluteal regions by MRI on 52 patients randomly selected [2]. Thus, it demonstrated the absence of anatomical variation in $59.6 \%$, a piriformis muscle which was bifid in $10.6 \%$ of the cases, hypertrophic in $13.5 \%$ and atrophic in $2.9 \%$. Patients with ischiatic hernias frequently present with symptoms of abdominal, pelvic, lower back or thigh pain. The abdominal CT scan performed in emergency makes it possible to carry out the topographic assessment of the lesion [3]. The hernia sac may contain the small intestine, ureter, ovary, colon or bladder. It may even be responsible for a neurological symptomatology by direct compression [4]. A ureter ischiatic hernia causing ureteral obstruction must be repaired surgically. The approach of this region requires dexterity to avoid a lesion of the superior gluteal vascular-nervous plexus.

\section{Literature review}

The supra-piriform hernia resulting in ureteric strangulation by

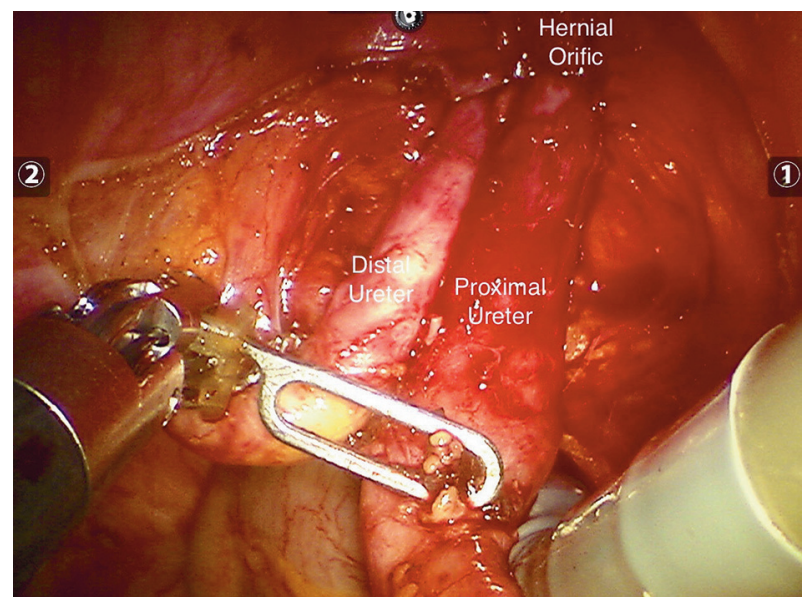

Figure 3. Intraoperative robot laparoscopic images. Proximal and distal ureter was incarcerated in the hernia orifice. Reduction not made to limit lesion of the ureter and to fill the orifice. 
the ischiatic foramen is exceptional. By frequency argument, the ureteral involvement by hernia in women is rather of femoral and inguino-scrotal seat in the man [5]. From difficult diagnosis, it can be responsible for chronic pain in women. The first case involving a supra-piriform hernia of the pelvic ureter was described (in the literature) in 1947 by Lindbom et al [6]. The clinical picture is often a urinary tract infection related to a ureter obstruction which describes a loop, like an omega, in the hernia responsible for dilated urinary tract upstream. Symptomatology may approach a nephritic colic attack. Different surgical techniques exist [7]. The gluteal approach is no longer recommended. Laparotomy is reserved when a large intestinal occlusion is associated. Laparoscopy reserved for experienced surgeons was described for the first time in 1999 by Gee et al during which a hernia reduction with prosthetic parietoplasty was performed [8]. In our case, we had only chosen to let ureteral portion inside hernia orifice. Apply prosthetic repair appear dangerous near superior gluteal vascular-nervous plexus.

In conclusion, ureteral hernia is a rare cause of obstructive pyelonephritis and the CT scan is the better exam to establish both positive and topographical diagnosis that will guide the surgeon. Anatomical repair by robot-assisted laparoscopy allows safe surgery for optimal functional outcome.

\section{Conflict of Interest}

None.

\section{References}

1. Golder W, Weiner G. [Body structure and radiation exposure in dynamic X-ray studies. A contribution to determining national reference values]. Rofo. 2001;173(8):756762.

2. Delabie A, Peltier J, Havet E, Page C, Foulon P, Le Gars D. [Relationships between piriformis muscle and sciatic nerve: radioanatomical study with 104 buttocks]. Morphologie. 2013;97(316):12-18.

3. Liberge R, Frampas E, Madoz A, Leaute F, Dupas B. Imagerie des hernies parietales abdominales. EMC - Radiologie Et Imagerie Medicale - Abdominale - Digestive. 2014;9:1-10.

4. Touloupidis S, Kalaitzis C, Schneider A, Patris E, Kolias A. Ureterosciatic hernia with compression of the sciatic nerve. Int Urol Nephrol. 2006;38(3-4):457-458.

5. Giglio M, Medica M, Germinale F, Raggio M, Campodonico F, Stubinski R, Carmignani G. Scrotal extraperitoneal hernia of the ureter: case report and literature review. Urol Int. 2001;66(3):166-168.

6. Lindbom A. Unusual ureteral obstruction by herniation of ureter into sciatic foramen. Acta radiol. 1947;28(3):225.

7. Pelissier E, Armstrong O, Ngo P. Traitement chirurgical des hernies ischiatiques ou sciatiques. EMC - Techniques chirurgicales - Appareil digestif. 2010;Article 40-156:15 .

8. Gee J, Munson JL, Smith JJ 3rd. Laparoscopic repair of ureterosciatic hernia. Urology. 1999;54(4):730-733. 